\title{
Lack of association between the pancreatitis risk allele CEL-HYB and pancreatic cancer
}

\author{
Koji Shindo ${ }^{1}$, Jun Yu ${ }^{1}$, Masaya Suenaga ${ }^{1}$, Shahriar Fesharakizadeh ${ }^{1}$, Koji Tamura ${ }^{1}$, \\ Jose Alejandro Navarro Almario ${ }^{1}$, Aaron Brant ${ }^{1}$, Michael Borges ${ }^{1}$, Abdulrehman \\ Siddiqui ${ }^{1}$, Lisa Datta ${ }^{4}$, Christopher L. Wolfgang ${ }^{2}$, Ralph H. Hruban ${ }^{1}$, Alison Patricia \\ Klein ${ }^{3,5}$ and Michael Goggins ${ }^{1,3,4}$ \\ ${ }^{1}$ Department of Pathology, The Sol Goldman Pancreatic Cancer Research Center, The Johns Hopkins University School of \\ Medicine, Baltimore, Maryland, USA \\ ${ }^{2}$ Department of Surgery, The Sol Goldman Pancreatic Cancer Research Center, The Johns Hopkins University School of \\ Medicine, Baltimore, Maryland, USA \\ ${ }^{3}$ Department of Oncology, The Sol Goldman Pancreatic Cancer Research Center, The Johns Hopkins University School of \\ Medicine, Baltimore, Maryland, USA \\ ${ }^{4}$ Department of Medicine, The Sol Goldman Pancreatic Cancer Research Center, The Johns Hopkins University School of \\ Medicine, Baltimore, Maryland, USA \\ ${ }^{5}$ Department of Epidemiology, Bloomberg School of Public Health, Baltimore, Maryland, USA
}

Correspondence to: Michael Goggins, email: mgoggins@jhmi.edu

Keywords: CEL, CELP, CEL-HYB, pancreatic cancer, chronic pancreatitis

Received: November 14, $2016 \quad$ Accepted: January 01, $2017 \quad$ Published: February 07, 2017

Copyright: Shindo et al. This is an open-access article distributed under the terms of the Creative Commons Attribution License 3.0 (CC BY 3.0), which permits unrestricted use, distribution, and reproduction in any medium, provided the original author and source are credited.

\section{ABSTRACT}

CEL-HYB is a hybrid allele that arose from a crossover between the $3^{\prime}$ end of the Carboxyl ester lipase (CEL) gene and the nearby CEL pseudogene (CELP) and was recently identified as a risk factor for chronic pancreatitis. Since chronic pancreatitis is a risk factor for the development of pancreatic cancer, we compared the prevalence of the CEL-HYB allele in patients with pancreatic ductal adenocarcinoma to spousal controls and disease controls. The CEL-HYB allele was detected using Sanger and next generation sequencing. There was no significant difference in the prevalence of the CEL-HYB allele between cases with pancreatic ductal adenocarcinoma compared to controls; $2.6 \%(22 / 850)$ vs. $1.8 \%(18 / 976)(p=0.35)$. CEL-HYB carriers were not more likely to report a history of pancreatitis. Patients with pancreatic cancer are not more likely than controls to be carriers of the CEL-HYB allele.

\section{INTRODUCTION}

Pancreatic ductal adenocarcinoma, more commonly known as pancreatic cancer, is the third-leading cause of cancer-related deaths in the United States with a 5-year overall survival of $8 \%$ [1]. This poor survival is related in part to the late presentation and rapid progression of disease [2]. A better understanding of the risk factors responsible for the development of pancreatic ductal adenocarcinoma, like chronic pancreatitis is needed not only to help identify individuals who might benefit from early detection strategies, but to refine our understanding of disease mechanisms. Patients with long-standing chronic pancreatitis have an increased risk of developing pancreatic cancer [3-6]. Among subjects with chronic pancreatitis, the risk of pancreatic cancer increases with increasing duration of pancreatitis and is highest among those with young-onset recurrent acute/chronic pancreatitis [7] as is seen in patients with inherited PRSSI mutations [8]. The risk of pancreatic cancer with chronic pancreatitis is higher among cigarette smokers [4] and may be greater among those who consume excess alcohol.

Although chronic pancreatitis is an important risk factor for pancreatic cancer development most of the mutated genes found to contribute to pancreatic cancer susceptibility when defective are classic tumor suppressor genes, such 
as BRCA2, ATM, PALB2, p16, and STK11 [9]. Common low penetrance variants in gene loci including $A B O, T E R T$ and $P D X 1$ that contribute to pancreatic cancer risk have been identified through genome-wide association studies [10-14], but much of the familial clustering of pancreatic cancer remains unexplained. Recently, a large scale familial pancreatic cancer sequencing initiative reported the results of whole exome sequencing of 598 kindred and found preliminary evidence that mutations in the pancreatitis susceptibility gene $C P A 1$, contributed to pancreatic cancer risk [15]. Deleterious mutations in $C P A 1$ were identified in four patients with familial forms of pancreatic cancer but not in controls [15]. Although PRSS1 and CPAI variants have been linked to pancreatic cancer risk, to date variants in other chronic pancreatitis susceptibility genes such as SPINK1 and CFTR have not been consistently found to be risk factors for pancreatic cancer [16-20].

Since much of the familial clustering of pancreatic cancer is not explained by germline alterations in known pancreatic cancer susceptibility genes [21-23], we evaluated whether gene variants associated with chronic pancreatitis could contribute to pancreatic cancer risk. Chronic pancreatitis encompasses a wide range of clinical and pathological findings $[4,24,25]$ and while it is typically a clinical syndrome associated with chronic pancreatic inflammation and fibrosis, chronic pancreatitis can be clinically silent. Although it is the clinical syndrome of long-standing chronic pancreatitis that is the established risk factor for pancreatic cancer, it is possible that clinically silent chronic pancreatitis contributes to pancreatic cancer development. In this study, we determined if a recently described risk factor for chronic pancreatitis, "CEL-HYB", might also be a risk factor for pancreatic cancer.

CEL-HYB is a hybrid allele (CEL-HYB) that has arisen from a crossing over event between the 3 ' end of the carboxyl ester lipase $(C E L)$ gene and the nearby $C E L$ pseudogene $(C E L P)$ [26, 27]. CEL encodes carboxyl ester lipase which is expressed in the acinar cells of the pancreas [28] and in mammary glands [29]. Mutations in the variable number of tandem repeat (VNTR) region of $C E L$ are a cause of young-onset diabetes (CEL-maturity onset diabetes of the young, CEL-MODY or MODY8) $[30,31,32]$. Molven et al. showed that CEL-HYB is significantly more prevalent in multiple different cohorts of European patients with chronic pancreatitis (2.6-4.3\%) than in controls (blood donors) (0.7-0.9\%) [26]. Here, we compared the prevalence of the CEL-HYB allele in a large series of patients with pancreatic cancer and in controls.

\section{RESULTS}

\section{Detection of CEL-HYB alleles}

The Agilent 2100 Bioanalyzer system was used to identify CEL-HYB alleles. The CEL-HYB allele was readily detected by PCR amplification in the two positive control samples (PTC1 and PTC2) (as two bands representing wildtype (CELP) and CEL-HYB alleles) (Figure 1A), whereas PCR products from control samples (HPDE, HPNE, and Capan2 DNA) had only one band representing the wild-type $(C E L P)$ allele. An example of the CEL-HYB allele detected by Bioanalyzer analysis is shown in Figure 1B.

\section{Sequencing of CEL-HYB allele by NGS}

We used Sanger sequencing to localize the nucleotide sequence difference between the CEL P and CEL-HYB alleles (Supplementary Figure 1) and next-generation sequencing to sequence the CEL-HYB allele (Figure 2A and 2B). A schematic figure of the CEL, CELP and CELHYB allele and amplicons obtained by PCR amplification is shown in Figure 2B. Positive controls and samples with CEL-HYB amplicons identified by Bioanalyzer all had CEL-HYB sequences in $\sim 50 \%$ of their reads by next-gen analysis whereas negative controls and samples without CEL-HYB amplicons had only the CELP sequence.

\section{CEL-HYB prevalence in cases and controls}

We identified a CEL-HYB allele in 22 of $850(2.6 \%)$ patients with pancreatic cancer, and 18 of $976(1.8 \%)$ controls, including $7 / 400(1.8 \%)$ of the healthy controls, $5 / 320(1.6 \%)$ of the spousal controls and 6/256 (2.3\%) other disease controls including 1 of 91 with a pancreatic neuroendocrine tumor (cases vs. controls, $\mathrm{p}=0.35$ ) (Table 1). Only 1 CEL-HYB carrier reported a personal history of pancreatitis.

\section{DISCUSSION}

We found no statistically significant difference in the prevalence of CEL-HYB in patients with pancreatic ductal adenocarcinoma compared to controls. It should be noted that many pancreatic cancer risk variants are lowpenetrant risk alleles [10-14] and we cannot rule out the possibility that CEL-HYB is a very low penetrant risk factor for pancreatic cancer development. Interestingly, Molven et al. found that the CEL-HYB allele has likely arisen through multiple independent recombination events since there was only limited linkage to nearby SNPs. This finding would indicate that the CEL-HYB allele would not be reliably reconstructed by imputing nearby SNPs and therefore may be easily detected using the SNP-based assays used for GWAS studies.

One notable finding in our study is that the prevalence of the CEL-HYB allele was higher in our control population $(1.8 \%)$ than in the European population studied by Molven et al $(\sim 0.8 \%)$ [26]. This probably reflects differences in the prevalence of this allele in different populations and highlights the need to account for ethnicity when comparing cases and controls. The finding that only one of the 
A [bp]
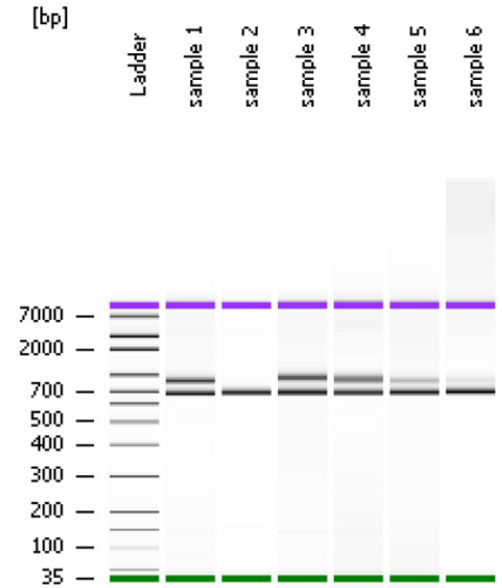

\begin{tabular}{|c|c|c|c|c|c|}
\hline $\begin{array}{c}\text { Sample } \\
1\end{array}$ & $\underset{\mathbf{2}}{\text { Sample }}$ & $\underset{3}{\text { Sample }}$ & $\begin{array}{c}\text { Sample } \\
4\end{array}$ & $\begin{array}{c}\text { Sample } \\
5\end{array}$ & $\underset{6}{\text { Sample }}$ \\
\hline \multirow[t]{4}{*}{ PTC1 } & HPDE & PTC2 & PTC1 & PTC1 & PTC1 \\
\hline & & & PTC2 & HPDE & HPDE \\
\hline & & & & & HPNE \\
\hline & & & & & $\begin{array}{c}\text { Capan } \\
2\end{array}$ \\
\hline
\end{tabular}

B

$[\mathrm{bp}]$
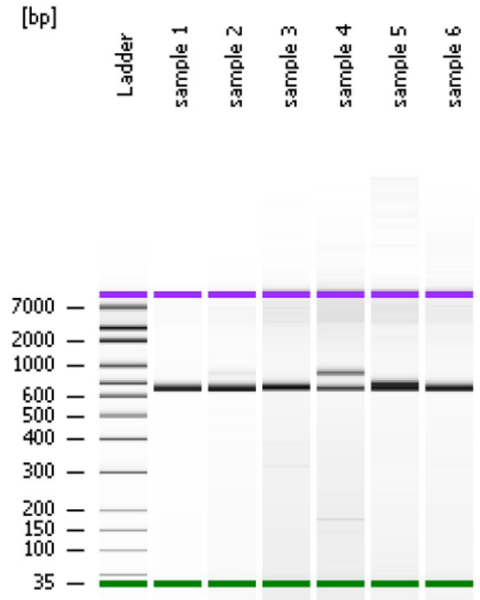

Sample 1
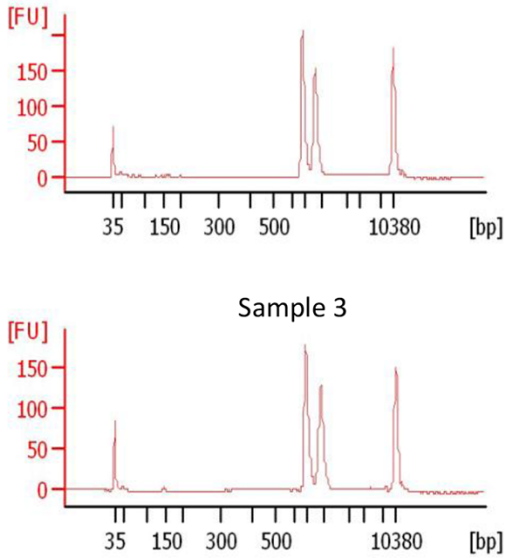

Sample 5

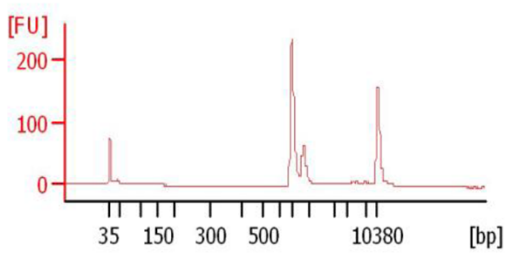

Sample 1

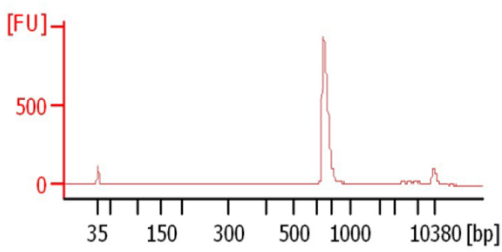

Sample 3

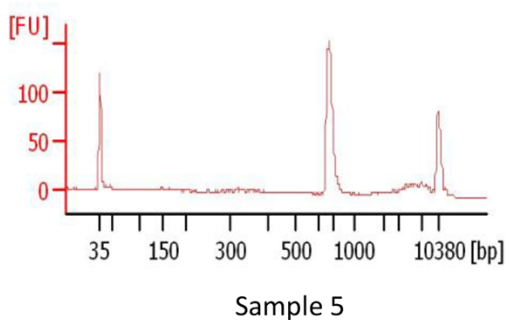

Sample 5

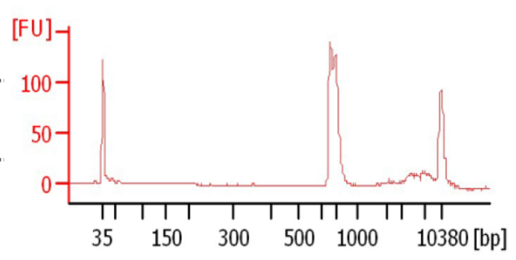

Sample 2

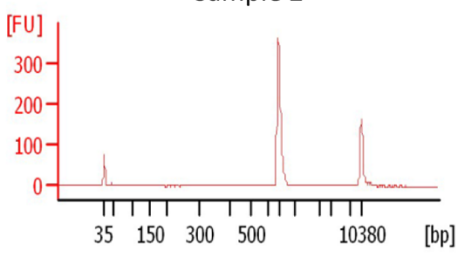

Sample 4

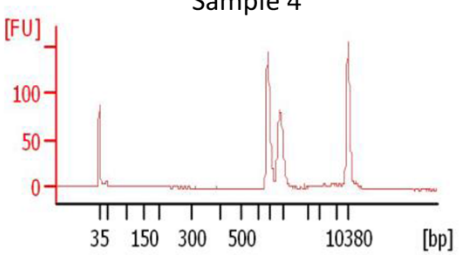

Sample 6

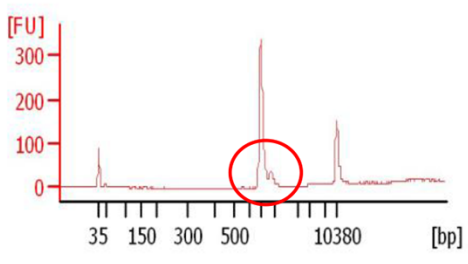

Sample 2
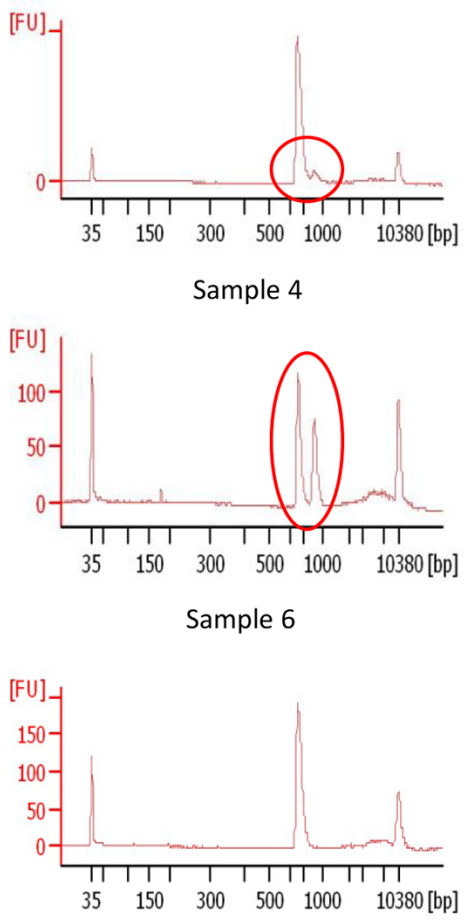

Figure 1: Bioanalyzer results of pooled $1^{\text {st }}$ PCR products. A. HPDE showed only one band whereas the positive control, PTC1, had one extra band. Sample 6 (circle) shows the detection of an extra band when the positive control DNA was mixed with 3 negative control DNA samples. B. Examples of CEL-HYB positive and negative samples identified by Bioanalyzer. A pool mixed with one positive case and three negative cases showed two bands (Sample 2). Individual analysis of each of these four samples detected the positive case (Sample 4), and three negative cases (Sample 3, 5, and 6). 
CEL-HYB carriers with pancreatic cancer reported a clinical history of chronic pancreatitis highlights the low-penetrant nature of CEL-HYB. Since the clinical syndrome of chronic pancreatitis is uncommon, it is likely that most CEL-HYB carriers do not develop pancreatitis. Interestingly, a recent study found that no association between a different CEL-HYB allele found in Asian populations and CP. [33] However, unlike

A

CELP

ctctgggctgatcggtccccagtgagcaccctgcctacttgggtggtctctcccctccagGAGTGCCAAGACCTACGCCTACCTGT TTTCCCATCCCTCTCGGATGCCCGTCTACCCCAAATGGGTGGGGGCCGACCATAGAGATGAGATCCAG TACATCTTTGGGGAGCCCTTTGCCACCCCACTCCGGGCTACCGGCCCCAAGACAGGACAGTCT CTAAGGCCATGACCGCCTACTGGACCAACTTTGCCAAAACAGGgtaagacgtgggttgagtgcagggcggagggccac agccgagaagggcctcccaccatgaggccttgttccctcacttgccagtggagggactttgggcaagtcacttaacctccccctgcatcggaa tccatgtgtgttt

CEL-HYB

ctctgggctgatcggtccccagtgagcaccctgcctacttgggtggtctctcccctccagGAGTGCCAAGACCTACGCCTACCTGT TTTCCCATCCCTCTCGGATGCCCGTCTACCCCAAATGGGTGGGGGCCGACCATGCAGATGACATTCAG TACGTTTTCGGGAAGCCCTTCGCCACCCCCACGGGCTACCGGCCCCAAGACAGGACAGTCTCT AAGGCCATGATCGCCTACTGGACCAACTTTGCCAAAACAGGgtaagacgtgggttgagtgcagggcggagggccacag ccgagaagggcctcccaccacgaggccttgttccctcacttgccagtggagggactttgggcaagtcacttaacctccccctgcatcggaatc catgtgtgttt

B

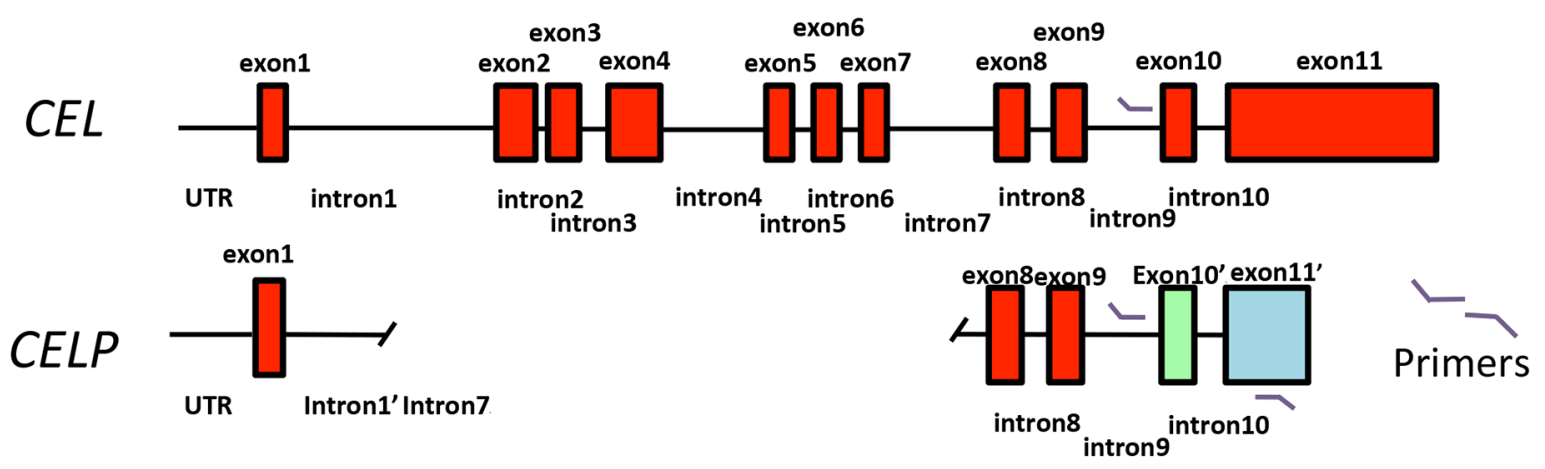

Exons $10^{\prime}$ and $11^{\prime}$ are partially same sequences with exons 10 and 11

$1^{\text {st }}$ PCR amplification

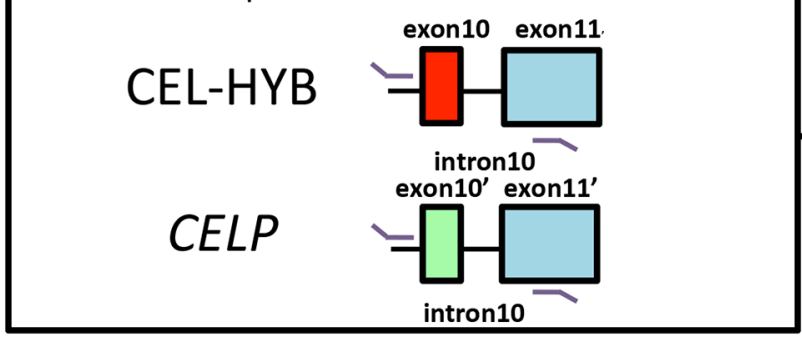

$2^{\text {nd }}$ PCR (nested PCR) amplification+NGS

CEL-HYB

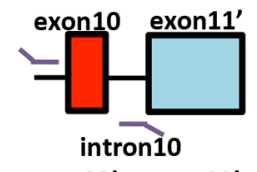

CELP

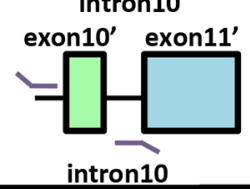

Figure 2: Detection of CEL-HYB by next-generation sequencing. A. CELP and representative CEL-HYB sequence are shown respectively. The area highlighted in yellow the nucleotide differences between CELP and CEL-HYB. B. A schematic diagram of the CEL and CELP loci. The red box corresponds to each exon. The green box represents exon10', and the blue box exon11' of CELP. PCR primer sites for the PCR products generated for $1^{\text {st }}$ PCR and the nested PCR used in NGS are shown in the lower panel. 
Table 1: CEL-HYB positive cases and disease controls

\begin{tabular}{|c|c|c|c|c|c|c|}
\hline Case \# & Diagnostic group & Primary diagnosis & Age & Sex & Race & $\begin{array}{c}\text { Past medical } \\
\text { history of } \\
\text { pancreatitis }\end{array}$ \\
\hline 1 & PDAC & PDAC & 51 & $\mathrm{~F}$ & Caucasian & No \\
\hline 2 & PDAC & PDAC & 72 & M & Caucasian & No \\
\hline 3 & PDAC & PDAC & 56 & $\mathrm{~F}$ & Caucasian & No \\
\hline 4 & PDAC & PDAC & 67 & M & Caucasian & Yes \\
\hline 5 & PDAC & PDAC & 44 & $\mathrm{~F}$ & Caucasian & No \\
\hline 6 & PDAC & PDAC & 72 & $\mathrm{~F}$ & Caucasian & No \\
\hline 7 & PDAC & PDAC & 70 & M & Caucasian & no \\
\hline 8 & PDAC & PDAC & 55 & M & Caucasian & No \\
\hline 9 & PDAC & PDAC & 51 & $\mathrm{~F}$ & Caucasian & No \\
\hline 10 & PDAC & PDAC & 54 & $\mathrm{~F}$ & Caucasian & No \\
\hline 11 & PDAC & PDAC & 40 & $\mathrm{~F}$ & Caucasian & No \\
\hline 12 & PDAC & PDAC & 68 & M & Caucasian & No \\
\hline 13 & PDAC & PDAC & 73 & M & Caucasian & No \\
\hline 14 & PDAC & PDAC & 64 & $\mathrm{~F}$ & Caucasian & No \\
\hline 15 & PDAC & PDAC & 69 & M & Caucasian & No \\
\hline 16 & PDAC & PDAC & 65 & M & Caucasian & No \\
\hline 17 & PDAC & PDAC & 51 & M & Caucasian & No \\
\hline 18 & PDAC & PDAC & 61 & $\mathrm{~F}$ & Caucasian & No \\
\hline 19 & PDAC & PDAC & 49 & M & Caucasian & No \\
\hline 20 & PDAC & PDAC & 44 & M & Caucasian & No \\
\hline 21 & PDAC & PDAC & 76 & M & Caucasian & No \\
\hline 22 & PDAC & PDAC & 69 & $\mathrm{~F}$ & Caucasian & No \\
\hline 23 & Disease controls & Duodenal adenoma & 54 & M & Caucasian & No \\
\hline 24 & Disease controls & Lymphoepithelial cyst & 57 & $\mathrm{~F}$ & Caucasian & No \\
\hline 25 & Disease controls & Solid pseudopapillary neoplasm & 31 & $\mathrm{~F}$ & Caucasian & No \\
\hline 26 & Disease controls & Ampullary adenoma & 79 & $\mathrm{~F}$ & Caucasian & No \\
\hline 27 & Disease controls & Duodenal adenocarcinoma & 62 & $\mathrm{~F}$ & Caucasian & No \\
\hline 28 & Disease controls & Pancreatic neuroendocrine tumor & 34 & $\mathrm{~F}$ & Caucasian & No \\
\hline $29-40$ & Healthy controls & Healthy controls & & & & \\
\hline
\end{tabular}

the European version, the Asian CEL-HYB variant is suspected to be functionally inactive. Further research is needed to determine the risk factors responsible for the development of chronic pancreatitis in CEL-HYB carriers.

In conclusion, we find no evidence for an association between the CEL-HYB allele and likelihood of developing pancreatic cancer.

\section{MATERIALS AND METHODS}

\section{Patients and specimens}

This study included patients who underwent pancreatic resection at the Johns Hopkins Hospital, spousal control individuals enrolled in the National Familial Pancreas Tumor Registry (NFPTR) at Johns Hopkins, and 
individuals enrolled in an inflammatory bowel disease study. The individuals included i) 850 patients (mean age $65 \pm 10.6$ years, 453 males, 753 Caucasian, 52 AfricanAmerican) who underwent pancreatic resection for clinically sporadic pancreatic ductal adenocarcinoma, ii) 320 spouses (without pancreatic cancer or pancreatitis) of individuals enrolled in The National Familial Pancreas Tumor Registry (NFPTR), iii) 400 healthy relatives participating in a study of inflammatory bowel disease, $v$ ) 256 individuals who underwent pancreatic resections for diseases unrelated to pancreatic ductal adenocarcinoma including patients who underwent pancreatic resection for a pancreatic neuroendocrine tumor $(n=91)$, duodenal cancer $(n=51)$, duodenal adenoma [12], ampullary adenoma [13], gall bladder cancer [7], carcinoid or GIST [17] other non-periampullary cancer [23], serous cystadenoma [25], solid pseudopapillary neoplasm [5], other non-neoplastic non pancreatic diseases [12]. DNA from spousal controls was isolated from peripheral blood mononuclear cells. DNA from cases and controls who underwent pancreatic resection was isolated from stored fresh-frozen normal tissue (duodenum, spleen, or pancreas) as previously described [10]. The clinicopathological characteristics of the cases and disease controls including their final diagnosis are presented in Table 1. All elements of this study were approved by the Johns Hopkins Institutional Review Board and written informed consent was provided from all patients.

\section{DNA extraction}

Genomic DNA was extracted using the QIAamp DNA Micro Kit (Qiagen) according to the manufacturer's instructions. DNA samples were quantified using the Quantifiler Human DNA Quantification kit (Applied Biosystems).

\section{CEL-HYB assay}

The CEL/CELP locus was amplified using Integrated DNA Technology (IDT) PCR primers; sense: 5' - gtctctgggetgatcggtc - 3' and antisense: 5' - cagactcggagttgcctgtc - 3'. SYBR green-based polymerase chain reaction (PCR) assays were used to differentiate wild-type alleles from CEL-HYB alleles. Two positive control samples (PTC1 and PTC2) were generously provided by Dr. Molven [26] and negative control samples (DNA from cell lines HPDE, HPNE, and Capan2) were used to validate the assay. The wild-type primers amplified the $C E L$ pseudogene (CELP) when no CEL-HYB was present and amplified both alleles when CEL-HYB was present. The reaction mixtures $(20 \mu \mathrm{l})$ consisted of $10 \mu \mathrm{l}$ SYBR Green Master Mix (Qiagen), 0.2 $\mu 1$ of each forward and reverse primers (primer set1: final concentration $0.1 \mu \mathrm{M}$ ), and $2 \mu 1$ genomic DNA of $6 \mathrm{ng}$ / ul with nuclease-free water. Amplification was performed using the SimpliAmp ${ }^{\mathrm{TM}}$ Thermal Cycler (ThermoFisher scientific) at the following cycling conditions: started with a denaturation step at $95^{\circ} \mathrm{C}$ for $12 \mathrm{~min}$ which was followed by 56 cycles of $95^{\circ} \mathrm{C}$ for $20 \mathrm{sec}, 60^{\circ} \mathrm{C}$ for $40 \mathrm{sec}$, and $72^{\circ} \mathrm{C}$ for $90 \mathrm{sec}$ and with a final extension at $72^{\circ} \mathrm{C}$ for $2 \mathrm{~min}$. PCR products were subsequently electrophoresed using an Agilent 2100 Bioanalyzer (Agilent Technologies, Loveland, CO USA) using the Agilent High Sensitivity DNA Kit following the manufacturer's protocol. We found that CEL-HYB alleles could be detected mixtures of PCR products from 4 individuals were pooled. Pooled samples containing CEL-HYB alleles were then run individually to identify the sample containing the allele. CEL-HYB alleles were confirmed using next-generation sequencing (NGS). Sanger sequencing (performed at the Johns Hopkins DNA sequencing Core) was used to identify the common and unique sequences between CEL-HYB and CELP.

\section{Next-generation sequencing (NGS)}

The libraries for NGS were prepared from a nested PCR; sense: 5'- adaptor sequence - gtctctgggctgatcggtc - 3' and antisense: 5' - aaacacacatggattccgatg - 3', which started with a denaturation step at $94^{\circ} \mathrm{C}$ for $3 \mathrm{~min}$, followed by 40 cycles of $94^{\circ} \mathrm{C}$ for $30 \mathrm{sec}, 58^{\circ} \mathrm{C}$ for $30 \mathrm{sec}$, and $68^{\circ} \mathrm{C}$ for $1 \mathrm{~min}$. Libraries were cleaned up using Agencourt AMPure XP Reagent (Beckman Coulter) on a magnet stand, eluted into low TE buffer and subsequently quantified using the Ion Quantification Kit (Life Technologies) following the manufacturer's protocols. The libraries were introduced with emulsion PCR reagents into the Ion OneTouch2 system (Life Technologies) for about 5 hours, where the libraries were ligated to Ion Sphere Particle (ISPs). The ISPs with the libraries were cleaned up and enriched in the Ion OneTouch ES (enrichment system) (Life Technologies) and subsequently loaded into an Ion Torrent Personal Genome Machine (PGM, Life Technologies) for sequencing. Post-sequencing data analysis, including alignment to the hg19 human reference genome, was done using the software Geneious (version R9, Auckland, New Zealand).

\section{Statistics}

The Chi-square test was used to compare the prevalence of CEL-HYB variants in cases vs. controls. SPSS software was used (v22, IBM). A 2-tailed $p<0.05$ was considered statistically significant.

\section{Abbreviations}

CEL: carboxyl ester lipase; CELP: carboxyl ester lipase pseudogene; CEL-HYB: CEL hybrid allele; PDAC: pancreatic ductal adenocarcinoma; PCR: polymerase chain reaction; PTC: positive control, NGS: next generation sequencing; VNTR: variable number tandem repeat; SNP: single-nucleotide polymorphism. 


\section{Author contributions}

Conceived and designed the experiments: $\mathrm{MG}, \mathrm{KS}$ and JY: acquisition of data (KS, JY, SF, JANA, AB, MB, $\mathrm{AS}, \mathrm{SB}, \mathrm{LD}, \mathrm{CW}, \mathrm{RHH}, \mathrm{AK}$ ); analysis and interpretation of data (KS, JY, MG, MS, SF, JANA, SB, LD); drafted the manuscript: KS, JY and MG. Statistical analysis; KS, Revised the manuscript and agreed with the manuscript's results and conclusions: all the authors, study support (NFPTR); obtained funding (MG), study supervision (MG).

\section{ACKNOWLEDGMENTS}

The authors thank all study participants and the members of The National Familial Pancreas Tumor Registry (NFPTR) for providing clinical data and samples. We also appreciate to Dr. Anders Molven and Dr. Karianne Fjeld for providing the CEL-HYB positive control samples.

\section{CONFLICTS OF INTEREST}

The authors have no conflicts to declare. The corresponding authors had full access to all of the data and take full responsibility for the veracity of the data and statistical analysis.

\section{GRANT SUPPORT}

This work was supported by NIH grants (CA62924, R01CA176828), Susan Wojcicki and Dennis Troper, and the Rolfe Pancreatic Cancer Foundation.

\section{REFERENCES}

1. Siegel RL, Miller KD, Jemal A. Cancer statistics, 2015. CA Cancer J Clin. 2015;65:5-29.

2. Yu J, Blackford AL, Dal Molin M, Wolfgang CL, Goggins M. Time to progression of pancreatic ductal adenocarcinoma from low-to-high tumour stages. Gut. 2015;64:1783-9.

3. Malka D, Hammel P, Maire F, Rufat P, Madeira I, Pessione F, Levy P, Ruszniewski P. Risk of pancreatic adenocarcinoma in chronic pancreatitis. Gut. 2002;51:849-52.

4. Andersen DK, Andren-Sandberg A, Duell EJ, Goggins M, Korc M, Petersen GM, Smith JP, Whitcomb DC. Pancreatitis-diabetes-pancreatic cancer: summary of an NIDDK-NCI workshop. Pancreas. 2013;42:1227-37.

5. Duell EJ, Lucenteforte E, Olson SH, Bracci PM, Li D, Risch HA, Silverman DT, Ji BT, Gallinger S, Holly EA, Fontham EH, Maisonneuve P, Bueno-de-Mesquita HB, et al. Pancreatitis and pancreatic cancer risk: a pooled analysis in the International Pancreatic Cancer Case-Control Consortium (PanC4). Ann Oncol. 2012;23:2964-70.
6. Maisonneuve P, Lowenfels AB, Bueno-de-Mesquita HB, Ghadirian P, Baghurst PA, Zatonski WA, Miller AB, Duell EJ, Boffetta P, Boyle P. Past medical history and pancreatic cancer risk: results from a multicenter case-control study. Ann Epidemiol. 2010;20:92-8.

7. Lowenfels $\mathrm{AB}$, Maisonneuve $\mathrm{P}$, DiMagno EP, Elitsur Y, Gates LK Jr, Perrault J, Whitcomb DC. Hereditary pancreatitis and the risk of pancreatic cancer. International Hereditary Pancreatitis Study Group. J Natl Cancer Inst. 1997;89:442-6.

8. Raimondi S, Lowenfels AB, Morselli-Labate AM, Maisonneuve P, Pezzilli R. Pancreatic cancer in chronic pancreatitis; aetiology, incidence, and early detection. Best Pract Res Clin Gastroenterol. 2010;24:349-58.

9. Bartsch DK, Gress TM, Langer P. Familial pancreatic cancer--current knowledge. Nat Rev Gastroenterol Hepatol. 2012;9:445-53.

10. Childs EJ, Mocci E, Campa D, Bracci PM, Gallinger S, Goggins M, Li D, Neale RE, Olson SH, Scelo G, Amundadottir LT, Bamlet WR, Bijlsma MF, et al. Common variation at $2 \mathrm{p} 13.3,3 \mathrm{q} 29,7 \mathrm{p} 13$ and $17 \mathrm{q} 25.1$ associated with susceptibility to pancreatic cancer. Nat Genet. 2015;47:911-6.

11. Childs EJ, Chaffee KG, Gallinger S, Syngal S, Schwartz AG, Cote ML, Bondy ML, Hruban RH, Chanock SJ, Hoover RN, Fuchs CS, Rider DN, Amundadottir LT, et al. Association of common susceptibility variants of pancreatic cancer in higher risk patients: a PACGENE study. Cancer Epidemiol Biomarkers Prev. 2016;25:1185-91.

12. Amundadottir L, Kraft P, Stolzenberg-Solomon RZ, Fuchs CS, Petersen GM, Arslan AA, Bueno-de-Mesquita HB, Gross M, Helzlsouer K, Jacobs EJ, LaCroix A, Zheng W, Albanes D, et al. Genome-wide association study identifies variants in the $\mathrm{ABO}$ locus associated with susceptibility to pancreatic cancer. Nat Genet. 2009;41:986-90. Epub 2009 Aug 2.

13. Petersen GM, Amundadottir L, Fuchs CS, Kraft P, Stolzenberg-Solomon RZ, Jacobs KB, Arslan AA, Buenode-Mesquita HB, Gallinger S, Gross M, Helzlsouer K, Holly EA, Jacobs EJ, et al. A genome-wide association study identifies pancreatic cancer susceptibility loci on chromosomes 13q22.1, 1q32.1 and 5p15.33. Nat Genet. 2010;42:224-8.

14. Wolpin BM, Rizzato C, Kraft P, Kooperberg C, Petersen GM, Wang Z, Arslan AA, Beane-Freeman L, Bracci PM, Buring J, Canzian F, Duell EJ, Gallinger S, et al. Genomewide association study identifies multiple susceptibility loci for pancreatic cancer. Nat Genet. 2014;46:994-1000.

15. Roberts NJ, Norris AL, Petersen GM, Bondy ML, Brand R, Gallinger S, Kurtz RC, Olson SH, Rustgi AK, Schwartz AG, Stoffel E, Syngal S, Zogopoulos G, et al. Whole genome sequencing defines the genetic heterogeneity of familial pancreatic cancer. Cancer Discov. 2016;6:166-75.

16. Matsubayashi H, Fukushima N, Sato N, Brune K, Canto M, Yeo CJ, Hruban RH, Kern SE, Goggins M. 
Polymorphisms of SPINK1 N34S and CFTR in patients with sporadic and familial pancreatic cancer. Cancer Biol Ther. 2003;2:652-5.

17. Malats N, Casals T, Porta M, Guarner L, Estivill X, Real FX. Cystic fibrosis transmembrane regulator (CFTR) DeltaF508 mutation and 5T allele in patients with chronic pancreatitis and exocrine pancreatic cancer. PANKRAS II Study Group. Gut. 2001;48:70-4.

18. McWilliams R, Highsmith WE, Rabe KG, de Andrade M, Tordsen LA, Holtegaard LM, Petersen GM. Cystic fibrosis transmembrane regulator gene carrier status is a risk factor for young onset pancreatic adenocarcinoma. Gut. 2005;54:1661-2.

19. Joergensen MT, Brusgaard K, Cruger DG, Gerdes AM, Schaffalitzky de Muckadell OB. Genetic, epidemiological, and clinical aspects of hereditary pancreatitis: a populationbased cohort study in Denmark. Am J Gastroenterol. 2010;105:1876-83.

20. Schubert S, Traub F, Brakensiek K, von Kopylow K, Marohn B, Maelzer M, Gaedcke J, Kreipe H, Stuhrmann M. CFTR, SPINK1, PRSS1, and CTRC mutations are not associated with pancreatic cancer in German patients. Pancreas. 2014;43:1078-82.

21. Slater EP, Langer P, Niemczyk E, Strauch K, Butler J, Habbe N, Neoptolemos JP, Greenhalf W, Bartsch DK. PALB2 mutations in European familial pancreatic cancer families. Clin Genet. 2010;78:490-4.

22. Jones S, Hruban RH, Kamiyama M, Borges M, Zhang X, Parsons DW, Lin JC, Palmisano E, Brune K, Jaffee EM, Iacobuzio-Donahue CA, Maitra A, Parmigiani G, et al. Exomic sequencing identifies PALB2 as a pancreatic cancer susceptibility gene. Science. 2009;324:217.

23. Klein AP. Identifying people at a high risk of developing pancreatic cancer. Nat Rev Cancer. 2013;13:66-74.

24. Whitcomb DC. Genetic risk factors for pancreatic disorders. Gastroenterology. 2013;144:1292-302.
25. Majumder S, Chari ST. Chronic pancreatitis. Lancet. 2016;387:1957-66.

26. Fjeld K, Weiss FU, Lasher D, Rosendahl J, Chen JM, Johansson BB, Kirsten H, Ruffert C, Masson E, Steine SJ, Bugert P, Cnop M, Grutzmann R, et al. A recombined allele of the lipase gene CEL and its pseudogene CELP confers susceptibility to chronic pancreatitis. Nat Genet. 2015;47:518-22.

27. Molven A, Njolstad PR, Weiss FU. Lipase gene fusion: a new route to chronic pancreatitis. Oncotarget. 2015;6:30443-4. doi: 10.18632/oncotarget.5454.

28. Lombardo D, Fauvel J, Guy O. Studies on the substrate specificity of a carboxyl ester hydrolase from human pancreatic juice. I. Action on carboxyl esters, glycerides and phospholipids. Biochim Biophys Acta. 1980;611:136-46.

29. Blackberg L, Angquist KA, Hernell O. Bile-salt-stimulated lipase in human milk: evidence for its synthesis in the lactating mammary gland. FEBS Lett. 1987;217:37-41.

30. Higuchi S, Nakamura Y, Saito S. Characterization of a VNTR polymorphism in the coding region of the CEL gene. J Hum Genet. 2002;47:213-5.

31. Torsvik J, Johansson S, Johansen A, Ek J, Minton J, Raeder H, Ellard S, Hattersley A, Pedersen O, Hansen T, Molven A, Njolstad PR. Mutations in the VNTR of the carboxyl-ester lipase gene (CEL) are a rare cause of monogenic diabetes. Human genetics. 2010;127:55-64.

32. Raeder H, Johansson S, Holm PI, Haldorsen IS, Mas E, Sbarra V, Nermoen I, Eide SA, Grevle L, Bjorkhaug L, Sagen JV, Aksnes L, Sovik O, et al. Mutations in the CEL VNTR cause a syndrome of diabetes and pancreatic exocrine dysfunction. Nat Genet. 2006;38:54-62.

33. Zou WB, Boulling A, Masamune A, Issarapu P, Masson E, Wu H, Sun XT, Hu LH, Zhou DZ, He L, Fichou Y, Nakano E, Hamada S, et al. No association between CEL-HYB hybrid allele and chronic pancreatitis in Asian populations. Gastroenterology. 2016;150:1558-1560. 